\title{
The forward premium anomaly is not as bad as you think
}

\author{
Richard T. Baillie ${ }^{\mathrm{a},{ }^{*},}$ Tim Bollerslev ${ }^{\mathrm{b}}$ \\ a Department of Economics, Michigan State University, East Lansing, MI 48824-1024, USA \\ ${ }^{\mathrm{b}}$ Department of Economics, Duke University, Durham, NC 27708-0097, USA
}

\begin{abstract}
The forward premium anomaly refers to the widespread empirical finding that the slope coefficient in the regression of the change in the logarithm of the spot exchange rate on the forward premium is invariably less than unity, and often negative. This "anomaly" implies the apparent predictability of excess returns over uncovered interest rate parity (UIP), and is conventionally viewed as evidence of a biased forward rate and/or of evidence of a timevarying risk premium. This paper presents a stylized model that imposes UIP and allows the daily spot exchange rate to possess very persistent volatility. The model is calibrated around realistic parameter values for daily returns and the slope coefficient estimates in the anomalous regressions with monthly data are found to be centered around unity, but are very widely dispersed, and converge to the true value of unity at a very slow rate. This theoretical evidence is shown to be consistent with the empirical findings for the monthly sample sizes typically employed in the literature. Hence, the celebrated unbiasedness regression does not appear to provide as much evidence as previously supposed concerning the possible bias of the forward rate. (c) 2000 Elsevier Science Ltd. All rights reserved.
\end{abstract}

JEL classification: C22; F31

Keywords: Forward premium; Uncovered interest rate parity; FIGARCH

\section{Introduction}

The forward premium anomaly refers to the widespread empirical finding that the returns on most freely floating nominal exchange rates up until the early 1990s appear

* Corresponding author. Tel.: +1-517-355-1864; fax: +1-517-432-1068.

E-mail address: baillie@pilot.msu.edu (R.T. Baillie). 
to be negatively correlated with the lagged forward premium or forward discount, and as such predict that a non-negative interest rate differential would, on average, result in an appreciating currency for the high interest rate country. This finding is usually interpreted as implying that the forward rate is a biased predictor of the future spot rate, and/or of evidence of a time-varying risk premium. Other interpretations to account for the phenomenon have resorted to explanations concerning peso problems, the irrational behavior of market participants and segmented markets, but none of these explanations have been fully satisfactory. Excellent surveys of the literature are provided by Hodrick (1987) and Engel (1996).

The forward premium anomaly has become a well established regularity and is generally regarded as being one of the most important unresolved paradoxes in international finance, and occupies a similar role to that of the equity premium puzzle in financial economics. The "anomaly" has prompted a number of studies to judge the performance of international asset pricing models in terms of whether or not they can reproduce the characteristic of a negative slope coefficient when the theoretical spot rate changes are regressed on the theoretical lagged forward premium; see e.g. Backus et al. (1996) and Bekaert (1996), Bekaert et al. (1997) and Macklem (1991). This paper provides evidence that this so-called anomaly may be viewed mainly as a statistical phenomenon that occurs because of the very persistent autocorrelation in the forward premium. Given the available small sample sizes it is simply not possible to tell, with any reasonable degree of accuracy, whether the forward rate constitutes an unbiased predictor of the corresponding future spot rate.

The plan for the rest of the paper is as follows. Section 2 provides a brief review of the pertinent economic foundations for the so-called anomalous regression, in which the change in the logarithm of the spot rate is regressed on the forward premia. Section 3 discusses some of the most important stylized empirical facts related to the distributional characteristics of spot and forward foreign exchange rates, along with the outcome of the celebrated anomalous regression. These results also highlight that with shorter sub-samples and more recent data the unbiasedness regression frequently generates large positive slope coefficients as well as the classic large negative coefficients that have received so much attention in the literature. ${ }^{1}$ Section 4 of the paper presents a simple stylized Uncovered Interest Rate Parity (UIP) asset pricing model, which imposes the joint assumptions of rational expectations and risk neutrality. The model is explicitly designed to capture the known essential empirical facts for spot exchange rates. In particular, the model allows for the daily spot rate to possess very small deviations from martingale behavior and very persistent volatility, while the forward rates are generated by assuming uncovered interest rate parity to be true. Section 5 describes the calibration of the stylized UIP model to a set of realistic parameter values based on a monthly sampling frequency and 1 month forward rates. The resulting simulation effectively demonstrates that although the

\footnotetext{
${ }^{1}$ For concreteness the empirical evidence and simulations reported throughout the paper will be focussed on the Deutschemark-US dollar (DM-\$) exchange rate. However, the same empirical regularities and conclusions hold true for other bilateral freely floating US dollar rates.
} 
slope coefficient estimates in the anomalous regression are centered around unity, they are also widely dispersed, and the anomalous regression slope coefficient estimate appears to have a very slow rate of convergence to its true value of unity. Section 6 concludes and discusses the interpretation of the evidence presented in the paper. The main conclusion is that the forward premium anomaly based on the standard unbiasedness regression does not provide sufficient statistical evidence to reject the hypothesis of the forward rate being an unbiased predictor of the future spot rate. Furthermore, if a time-varying risk premium does exist, then the evidence suggests that it is extremely small at the monthly level.

\section{Economic foundations}

In the following $S_{t}$ denotes the spot exchange rate at time $t$, while $F_{t, l}$ refers to the forward exchange rate at time $t$, for delivery at time $t+l$. Corresponding logarithmic values are denoted by the lower case variables, $s_{t}$ and $f_{t, l}$, respectively. All rates are denominated with the US dollar as the numeraire currency. Also, $i_{t, l}$ denotes the dollar return on an $l$-period risk free dollar denominated bond, whereas $i_{t, l}^{*}$ is the foreign currency return on a risk free bond denominated in terms of the foreign currency.

The Covered Interest Rate Parity (CIP) condition then states that $\left(f_{t, l}-s_{t+l}\right)=$ $\left(\mathrm{i}_{t, l}-\mathrm{i}_{t, l}^{*}\right)$, and apart from extremely small transactions costs, is known to hold as an identity. The central hypothesis of interest in the present paper is the Uncovered Interest Rate Parity (UIP) condition, which states that,

$$
E_{t}\left(\Delta s_{t+l}\right)=\left(f_{t, l}-s_{t}\right)=\left(i_{t, l}-i_{t, l}^{*}\right),
$$

where $E_{t}(\cdot)$ denotes the mathematical expectation conditioned on the set of all relevant information at time $t$. Hence the expected rate of appreciation (depreciation) should be equal to the current forward premium, $\left(f_{t, l}-s_{t}\right)$.

The UIP hypothesis is typically justified through the joint assumptions of rational expectations, risk neutrality, free capital mobility and the absence of taxes on capital transfers. Taken together, these assumptions imply that the expected real returns in the forward market must be zero. That is,

$$
E_{t}\left[\left(F_{t, l}-S_{t+l}\right) / P_{t+l}\right]=0,
$$

where $P_{t}$ denotes the domestic dollar price level. Also, by a Taylor series expansion of Eq. (2) to second order terms,

$$
E_{t}\left(s_{t+l}\right)-f_{t, l}=-\frac{1}{2} \cdot \operatorname{Var}_{t}\left(s_{t+l}\right)+\operatorname{Cov}_{t}\left(s_{t+l} p_{t+l}\right),
$$

where $p_{t}$ refers to the logarithmic price level. Note that, even under rational expectations and risk neutrality, the right-hand side of Eq. (3) contains the two conditional second moment terms. These are sometimes referred to as the Jensen inequality terms. 
More generally, in the context of the standard discrete time, consumption-based asset pricing model, the risk adjusted equivalent to Eq. (2) should be specified in terms of the real returns over the current and future consumption streams of the representative investor,

$$
E_{t}\left\{\left[\left(F_{t, l}-S_{t+l}\right) / P_{t++}\right] U^{\prime}\left(C_{t+l}\right) / U^{\prime}\left(C_{t}\right)\right\}=0,
$$

where $U^{\prime}\left(C_{t+l}\right) / U^{\prime}\left(C_{t}\right)$ equals the marginal rate of substitution in terms of utility derived from current and future consumption. The analogue to Eq. (3) therefore takes the form,

$$
E_{t}\left(s_{t+l}\right)-f_{t, l}=-\frac{1}{2} \operatorname{Var}_{t}\left(s_{t+l}\right)+\operatorname{Cov}_{t}\left(s_{t+l} p_{t+l}\right)+\operatorname{Cov}_{t}\left(s_{t+l} q_{t+l}\right)
$$

where $q_{t+l}$ denotes the logarithm of the intertemporal marginal rate of substitution. The last term,

$$
\rho_{t, l}=\operatorname{Cov}_{t}\left(s_{t+l} q_{t+l}\right),
$$

is a time-dependent risk premium, which has been the subject of many, largely unsuccessful, empirical investigations for explaining deviations from UIP. The large empirical literature on testing the UIP condition has been surveyed by Hodrick (1987), Baillie (1989) and Engel (1996).

\section{Empirical evidence}

Most of the earlier regression based tests involving the levels, $F_{t, l}=E_{t}\left(S_{t+l}\right)$, or the logarithmic levels, $f_{t, l}=E_{t}\left(s_{t+l}\right)$, were unable to reject the UIP hypothesis. Meanwhile, interest in the literature has been particularly focused on the relationship in Eq. (1) and the regression, ${ }^{2}$

$$
s_{t+l}-s_{t}=\alpha_{l}+\beta_{l}\left(f_{t, l}-s_{t}\right)+u_{t+l, l} .
$$

It follows that irrespective of the sampling frequency, $l$, the UIP hypothesis implies that $\alpha_{l}=0$ and $\beta_{l}=1$. If the sampling frequency is equal to the maturity time of the forward contract, so that $l=1$, then $u_{t+1,1}$ will be serially uncorrelated. ${ }^{3}$

The forward premium anomaly concerns the fact that with spot and forward rates for the 1970s and 80s the estimated slope coefficients are invariably found to be

\footnotetext{
${ }^{2}$ As discussed further below, both spot forward exchange rates are invariably considered to be $I(1)$ variables, so that the regression in levels will give rise to non-standard rates of convergence, rendering the traditional OLS-based inference procedures inappropriate.

${ }^{3}$ For notational simplicity, we shall omit the maturity time subscript whenever $l=1$. More general sampling schemes with $l>1$ give rise to an overlapping data problem and $(l-1)$ th order serial correlation in $u_{t+l, l}$.
} 
negative. ${ }^{4}$ This evidence has often been attributed to the existence of a significant time-dependent risk premium as defined in Eq. (6), so that

$$
E_{t}\left(s_{t+l}-s_{t}\right)=\left(f_{t, l}-s_{t}\right)+\rho_{t, l} \text {. }
$$

As noted by Fama (1984), a population value of $\beta_{l}<0$ implies that $\operatorname{Cov}\left[E_{t}\left(s_{t+l}-s_{t}\right) \rho_{t, l}\right]<0$ and also that $\operatorname{Var}\left(\rho_{t, l}\right)>\operatorname{Var}\left[E_{t}\left(s_{t+l}-s_{t}\right)\right]$. Hence a negative $\hat{\beta}_{l}$ coefficient implies a negative sample covariance between the risk premium and the expected rate of appreciation. For instance, McCallum (1994) reports estimated slope coefficients around -4 for several different currencies. This value of $\hat{\beta}_{l}=-4$ implies that $\operatorname{Var}\left(\rho_{t, l}\right) \geq 5 \operatorname{Var}\left(f_{t, l}-s_{t}\right)$, which indicates an extraordinarily high variability of the risk premium. Thus, a reasonable conclusion is that the size and volatility of the empirical risk premium are either surprisingly large, or that there is something fundamentally deficient with much of the previous econometric work in this area.

Previous explanations of the forward premium anomaly have included "peso problem" effects, e.g. Evans and Lewis (1995), and the importance of learning and heterogenous beliefs, e.g. Frankel and Froot (1987). Another possibility is that estimation of Eq. (7) may involve a mis-specification since the conditional variance and covariance terms featured in Eqs. (3) and (5) are neglected. In response to this, some previous studies have estimated a version of Eq. (7) of the form,

$$
s_{t+l}-s_{t}=\alpha_{l}+\beta_{l}\left(f_{t, l}-s_{t}\right)+\delta_{l} \operatorname{Var}_{t}\left(s_{t+l}-s_{l}\right)+u_{t+l, l},
$$

in which the $\delta_{l} \operatorname{Var}_{t}\left(s_{t+l}-s_{l}\right)$ term is replaced with the conditional variance of the innovation process. For instance, Baillie and Bollerslev (1990) estimated a multivariate (four) country version of Eq. (9) with the $\delta_{l}$ coefficients unrestricted. The $95 \%$ confidence interval around the point estimate of $\delta_{l}$ included the value $1 / 2$ predicted by theory. In a related article by Bekaert and Hodrick (1993), the value of $\delta_{l}$ is explicitly restricted to $1 / 2$. However, both studies were subsequently unable to either find a statistically satisfactory model for the risk premium or to explain the anomalous regression results of $\hat{\beta}_{l}<0$.

To highlight the above empirical regularities, consider a sample of monthly observations on the DM-\$ spot and 1-month forward rates from January 1974 to December 1991, realizing a total of 215 observations; i.e. $S_{t}$ and $F_{t, 1} \equiv F_{t}$, for $t=1,2, \ldots, 215$. The rates were originally provided by Data Resources Incorporated (DRI) and are recorded at the close of trading on the last business day of each month. These same rates have previously been analyzed by Baillie and Bollerslev (1994) and Crowder (1994).

There is widespread agreement that the logarithmic spot and forward rates are both integrated of order one, or $I(1)$, so that the corresponding returns are stationary, or $I(0)$, variables. Both monthly and higher frequency daily returns also appear to

\footnotetext{
${ }^{4}$ For instance, Froot and Thaler (1990) report that the mean value of $\hat{\beta}_{l}$ across 75 published studies is -0.88 . Also, Bansal (1997) has found that the sign of the slope coefficient depends on the sign of the cross-country interest rate differential, so that when the differential is negative, the estimated slope coefficients are typically not significantly different from zero.
} 
be well approximated by a martingale model. However, while daily exchange rate returns exhibit pronounced volatility clustering, there are little if any ARCH effects discernible at the monthly frequency; see e.g. Baillie and Bollerslev (1989). For instance, the Ljung-Box portmanteau test for up to 12th order serial correlation in the squared monthly DM- $\$$ returns is $Q^{2}(12)=6.91$. Also, the monthly sample standard deviation of the percentage spot returns, $100\left(s_{t+1}-s_{t}\right)$, equals 2.75 , corresponding to an annualized volatility of around $10 \%$.

Meanwhile, the monthly forward premium is much less variable, with a sample standard deviation of $100\left(f_{t}-s_{t}\right)$ equaling only 0.217 . The forward premia also generally display very persistent, slowly decaying autocorrelations; see e.g. Baillie and Bollerslev (1994), Bekaert and Hodrick (1992) and Bekaert (1995). In particular, the Ljung-Box portmanteau test for up to 12 th order serial correlation in the monthly $\mathrm{DM}-\$$ premium is $Q(12)=773$. The extreme persistence of the autocorrelations of the forward premium has even persuaded some authors that it may contain nonstationary components; e.g. Evans and Lewis (1995) and Crowder (1994). However, Baillie and Bollerslev (1994) have argued that the temporal dependencies in the forward premium are better described by a fractionally integrated, or $I(d)$ process, where $0<d<1$, so that all shocks eventually dissipate but at a very slow hyperbolic rate of decay. One implication of this line of work is that the standard unbiasedness regression in Eq. (7) may not be "balanced", in the sense that the orders of integration of the dependent and explanatory variables are not the same. ${ }^{5}$ Formal theoretical results along these lines based on the notion of fractional cointegration have recently been pursued by Maynard and Phillips (1998). The present paper takes a different approach in considering artificially generated time series for $s_{t}$ and $f_{t}$ that accord with the stylized empirical facts, but where the true data generating process is motivated by the economic relationships discussed in Section 1 above, rather than by a purely expedient time series approach.

The principle focus of this study is the anomalous regression in Eq. (7), and the estimated slope coefficient based on the 215 monthly DM- $\$$ rates of $\beta=-2.23$, with an OLS standard error of 0.99 . Thus, not only is the estimate for $\beta$ significantly different from the UIP hypothesis of unity, it is significantly less than zero based on the conventional asymptotic distribution theory, so that over the sample period, a positive forward premium was, on average, associated with a DM-\$ depreciation. This anomalous finding is entirely consistent with the evidence reported in the existing literature for other currencies and sampling frequencies using data up until the early $1990 \mathrm{~s} .{ }^{6}$ At the same time, the low $R^{2}=0.038$ indicate that the forward premium actually explains very little of the monthly spot rate appreciation.

${ }^{5}$ In this situation a test of the UIP condition with $l=1$ should be based on estimating the relationship,

$$
s_{t+1}-s_{t}=\alpha+\beta\left[1-(1-L)^{1-d}\right](1-L)^{d} \phi(L)\left(f_{t}-s_{t}\right)+u_{t+1},
$$

and testing whether $\alpha=0, \beta=1$, and $u_{t+1}$ is serially uncorrelated.

${ }^{6}$ The estimated slope coefficients and OLS standard errors for the US dollar versus the British pound, the Japanese yen, and the Canadian dollar over the same monthly sample period from January 1974 to December 1991 are $-2.34(0.61),-0.97(0.37)$ and $-1.43(0.41)$, respectively. Also, the corresponding 
The anomalous regression estimates become more extreme when considering results obtained with shorter time spans and more recent observations. Fig. 1 depicts estimates of $\beta$ from 2085 -year rolling regressions, with the first estimate obtained by beginning at March 1973 and using a total of 60 observations through to February 1978. The next estimate was obtained by using data from April 1973 through to March 1978 until the final estimate was based on data from December 1990 to November 1995. The sequence of estimated $\beta$ values varies considerably over the different sample periods. Interestingly, the last 20 regressions for the sub-period from December 1986 to November 1991 until the final sub-period from December 1990 to November 1995, all realize positive slope coefficient estimates, with the largest being 3.52. Correspondingly, there is a period in the middle of the floating regime where the estimated $\beta$ coefficients are statistically negative based on the conventional asymptotic two standard error bands. This era extends from the October 1980 through to September 1985 sub-period to the June 1985 to May 1990 sub-period. The largest negative coefficient in this period is -13.00 . Hence, contrary to conventional wis-

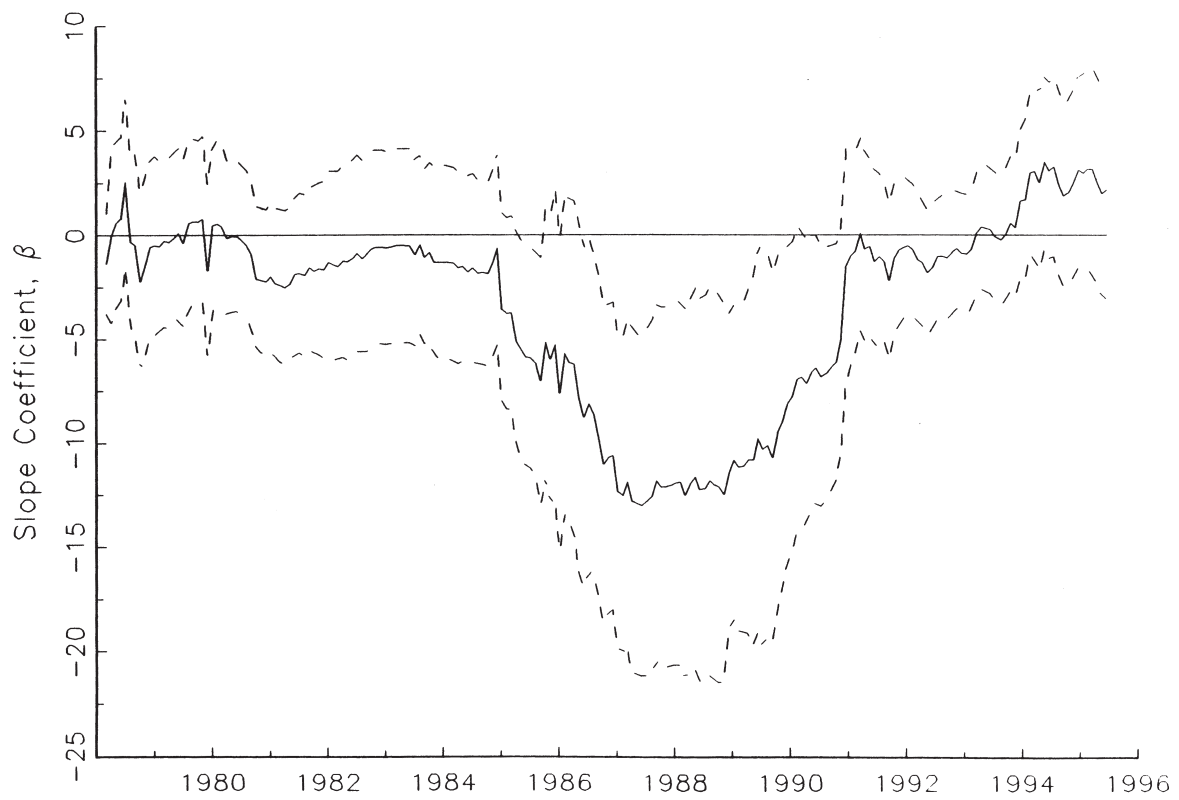

Fig. 1. Rolling 5-year DM- $\$$ unbiasedness regressions. The figure graphs the 208 slope coefficients obtained from the unbiasedness regression in Eq. (7) based on rolling monthly 5-year sub-samples for the DM-\$ exchange rate beginning with the sample from March 1973 until February 1978, ending with the 5-year sample from December 1990 through to November 1995. The dashed lines give the conventional two OLS standard error confidence bands.

estimates for the Yen-Deutschemark, Deutschemark-Pound, and Yen-Pound are - 1.24 (1.50), $0.16(0.30)$ and $-0.53(0.92)$, respectively. 
dom, the estimated slope coefficient from the anomalous regression exhibits substantial variation, and for the 5-year regressions depicted in Fig. 1, many of the more recent slope coefficients are actually positive, albeit not statistically significant when judged by the usual $95 \%$ confidence bands. Very similar results were obtained for other US dollar denominated currencies. Of course, the estimated $\beta$ coefficients tend to be highly cross-correlated over time and across countries. Nonetheless, these findings clearly suggest that for many of the sample sizes encountered in practice, the estimated slope coefficient is likely to be uninformative about the true value of $\beta_{l}$. We now turn to a discussion of a relatively simple stylized UIP model which validates this conjecture.

\section{The stylized UIP model}

The model is designed to represent the known stylized facts concerning the time series properties of spot and forward exchange rates, while at the same time adhering to the UIP condition. The model is calibrated to a "monthly" observation frequency, so that the unit time interval corresponds to 1 month. However, the actual data generating mechanism for the spot rate is formulated at the "daily" frequency corresponding to 21 working "days" per "month". Specifically,

$$
\begin{aligned}
& s_{\tau}=q_{\tau}+z_{\tau}, \\
& q_{\tau}=q_{\tau-1 / 21}+\eta_{\tau}, \\
& z_{\tau}=\phi z_{\tau-1 / 21}+\epsilon_{\tau},
\end{aligned}
$$

where $\tau=0,1 / 21,2 / 21, \ldots$, and $\eta_{\tau}$ and $\epsilon_{\tau}$ are serially and mutually uncorrelated white noise processes with means equal to zero and unconditional variances denoted by $\sigma_{\eta}^{2}$ and $\sigma_{\epsilon}^{2}$, respectively. This formulation for the conditional mean dependencies in the "daily" spot rate in terms of the sum of a permanent unit root component, $q_{\tau}$, and a transitory $A R(1)$ component, $z_{\tau}$, directly mirrors the FADS model used by Fama and French (1988) and Poterba and Summers (1988) in their analyses of longhorizon predictability in equity returns. Rearranging Eqs. (10)-(12), it follows that

$$
\left(1-L^{1 / 21}\right) s_{\tau}=\eta_{\tau}+\left(1-L^{1 / 21}\right)\left(1-\phi L^{1 / 21}\right)^{-1} \epsilon_{\tau},
$$

so that the "daily" spot rate can be represented as an $\operatorname{ARIMA}(1,1,1)$ model. Clearly, with $\phi$ equal to one, the spot rate is identically a martingale. With $\phi$ close, but very slightly less than unity, the change in the spot rate will exhibit some small degree of autocorrelation. In particular, it is relatively straightforward to show that the first order autocorrelation coefficient for the calibrated "monthly" spot rate series is,

$$
\operatorname{Corr}\left[\left(s_{t+1}-s_{t}\right)\left(s_{t}-s_{t-1}\right)\right]=-\left(1-\phi^{21}\right)^{2}\left[21\left(1-\phi^{2}\right) \sigma_{\eta}^{2}+2 \cdot\left(1-\phi^{21}\right) \sigma_{\epsilon}^{2}\right]^{-1},
$$

which is less than zero for $\phi<1$. Consistent with the empirical evidence discussed in the previous section, in the simulations of the model reported on below we took $\phi=0.995$ and $\phi=0.999$, which imply near martingale behavior at the "daily" level. Along with the other model parameters, these values for $\phi$ also imply that for none 
of the designs were the resulting population values for the first order "monthly" autocorrelations less than -0.04 .

Although daily asset returns generally exhibit very little serial dependence, it is well known that they exhibit substantial ARCH effects, with periods of relative tranquility and turbulence. This volatility clustering phenomenon in daily spot exchange rates has been modeled by many previous authors; see e.g. Baillie and Bollerslev (1989) and Hsieh (1989). More recently Baillie et al. (1996) have argued that the so-called Fractionally Integrated GARCH, or FIGARCH, model provides a better representation of the daily DM- $\$$ spot exchange rate conditional variance process than either the stable $\operatorname{GARCH}(1,1)$ or $\operatorname{IGARCH}(1,1)$ processes employed in previous studies. The FIGARCH process implies a slow hyperbolic rate of decay for the lagged squared innovations and quite persistent impulse response weights, although not the complete persistence associated with the integrated IGARCH process. Thus, the volatility processes for the transitory innovations in Eq. (12), $\epsilon_{\tau}$, are here assumed to follow the FIGARCH $(1, d, 0)$ process,

$$
\begin{aligned}
& \epsilon_{\tau} \sigma_{\tau}^{1} \text { i.i.d. } N(0,1), \\
& \left(1-\theta L^{1 / 21}\right) \sigma_{\tau}^{2}=\omega+\left[1-\theta L^{1 / 21}-\left(1-L^{1 / 21}\right)^{d}\right] \epsilon_{\tau}^{2},
\end{aligned}
$$

where $\tau=0,1 / 21,2 / 21, \ldots$. Alternatively, the equation for the "daily" conditional variance for $\epsilon_{\tau}$ may be expressed more succinctly as,

$$
\sigma_{\tau}^{2}=\omega(1-\theta)^{-1}+\lambda\left(L^{1 / 21}\right) \epsilon_{\tau}^{2}
$$

where the coefficients $\lambda(\cdot)$ are defined by $\lambda_{k}=\Gamma(k+d-1) \Gamma(k)^{-1} \Gamma(d)^{-1}[1-\theta-(1-$ d) $k^{-1}$. By Stirling's formula, it follows that for large lags $k, \lambda_{k} \approx(1-$ $\theta) \cdot \Gamma(d)^{-1} \cdot k^{d-1}$, which implies a slow hyperbolic rate of decay for the corresponding impulse response weights. ${ }^{7}$

The unconditional variance of the FIGARCH model does not formally exist. When generating the FIGARCH realizations the corresponding infinite $\mathrm{ARCH}$ representation defined by the $\lambda(\cdot)$ polynomial above was truncated at a lag length of 1000 , with the unconditional variance of this approximation fixed at $\sigma_{\epsilon}^{2}$. As such, the simulation design effectively mimics a covariance stationary GARCH model with very long memory. In keeping with the findings for the daily DM- $\$$ rates reported in Baillie et al. (1996), the parameters governing the dynamic dependencies in this approximate $\operatorname{FIGARCH}(1, d, 0)$ model were fixed at $\theta=0.7$ and $d=0.75$ across all designs. The two remaining unconditional variance parameters, $\sigma_{\eta}^{2}$ and $\sigma_{\epsilon}^{2}$, were chosen so that the "annual", or 250 "days" volatility of the simulated spot rate series,

$$
\operatorname{Var}\left[\left(s_{\tau+250 / 21}-s_{\tau}\right)\right]^{1 / 2}=\left[250 \sigma_{\eta}^{2}+2 \sigma_{\epsilon}^{2}\left(1-\phi^{250}\right)\left(1-\phi^{2}\right)^{-1}\right]^{1 / 2},
$$

\footnotetext{
${ }^{7}$ An interesting issue concerns the origins of this long-run persistence in the volatility process. As shown by Ding and Granger (1996), the aggregation of martingale processes with stable GARCH(1,1) volatility, produces in the limit hyperbolically decaying autocorrelations for the squared aggregate process. In a closely related context, Andersen and Bollerslev (1997) demonstrate that the aggregation of heterogenous news arrival processes may give rise to a long-memory stochastic volatility type model.
} 
equals $12 \%$. Finally, the permanent errors, $\eta_{\tau}$, were assumed to be i.i.d. normally distributed. ${ }^{8}$ This model design will be referred to as $\mathrm{G}$ in the subsequent analysis. ${ }^{9}$ For comparison purposes, we also report the simulation results from a model termed $\mathrm{N}$, in which the two innovations are both i.i.d. normally distributed, thus ignoring the long memory GARCH effects.

The final key equation of the model stipulates that the 1-month forward rates adhere to the UIP condition in Eq. (3). However, monthly goods market variables are generally too smooth to generate significant covariation with exchange rates, and prior empirical studies have generally been unable to find any evidence that the conditional covariance between spot rates and prices, or between spot rates and consumption or money are significantly different from zero at the monthly level. Consequently, the last term in Eq. (3), or equivalently the last two terms in Eq. (5), are simply omitted from the return generating process for $f_{\tau}$,

$$
f_{\tau}=E_{\tau}\left(s_{\tau+1}\right)+\frac{1}{2} \operatorname{Var}_{\tau}\left(s_{\tau+1}\right)+\kappa+\xi_{\tau}
$$

where $\tau=0,1 / 21,2 / 21, \ldots$. The value of the constant, $\kappa$, is fixed at $1 / 2 \operatorname{Var}\left(s_{\tau+1}-s_{\tau}\right)$. This term is included to ensure that the logarithmic forward rate is unconditionally unbiased, and may be viewed as proxy for the omitted time-invariant covariance terms. The last term in Eq. (15) mimics bid-ask bounce effects, but it is extremely small and immaterial to any of the results with data available only at the "monthly" frequency; i.e. $\left(s_{t} f_{t}\right)$ for $t=1,2, \ldots{ }^{10}$

One immediate implication of the model for $f_{\tau}$ Eq. (15), is that the forward rate should be cointegrated with the spot rate, with a cointegration parameter of approximately unity. This again is consistent with the existing empirical evidence. It follows also from Eqs. (10)-(15), that the process for the "daily" forward rate may be written as,

$$
f_{\tau}=q_{\tau}+\phi^{21} z_{t}+\frac{1}{2} \sum_{j=1,21}\left[\operatorname{Var}_{\tau}\left(\eta_{\tau+j / 21}\right)+\phi^{2(21-j)} \operatorname{Var}_{\tau}\left(\epsilon_{\tau+j / 21}\right)\right]+\kappa+\xi_{\tau}
$$

This representation highlights the fact that the 1-month forward rate depends not only on the current level of the permanent and transitory components of the spot rate, but also on the accumulated conditional variances of the "daily" spot rate innovations.

\footnotetext{
${ }^{8}$ All of the normal random variables were generated by the RNDNS routine in the GAUSS computer package.

9 An analogous design in which the permanent innovations, $\eta_{\tau}$, in Eq. (11) were governed by a FIGARCH $(1, d, 0)$ process, and the transitory innovations, $\epsilon_{\tau}$, were normally distributed, was also investigated. The results from these experiments are comparable and available upon request.

${ }^{10}$ Specifically, the $\xi_{t}$ term is generated as an i.i.d. normal random variable with a mean of zero and a standard deviation of 0.005 , which corresponds to the median quoted spread in the DM- $\$$ interbank market; see Bollerslev and Melvin (1994). As a reference point, the standard deviation of the 5 min change in the logarithmic DM-\$ spot rate is approximately equal to 0.005 .
} 
It should be noted that a model calibrated using a stable $\operatorname{GARCH}(1,1)$ process is not particularly interesting in this context, since it fails to replicate the long memory characteristics present in either the spot returns volatility process, or the conditional mean of the forward premium. Indeed, some initial experimentation found stable, calibrated GARCH models generated forward premiums without the very persistent autocorrelation found in actual empirical forward premium series. This therefore removes the crucial ingredient of the anomaly and OLS estimations of the resulting forward premium regressions were very similar to those when the innovations were assumed to be i.i.d. normal. Hence, in order to conserve space, the details of these simulations are not reported in the tables below.

\section{The simulated stylized UIP model}

The stylized UIP model set out above is designed to be consistent with the known time series properties of daily spot exchange rates. The consequent generated "monthly" forward rate is a distinctly unusual non-linear process, given by the sum of an MA(21) process and a long-memory FIGARCH in-the-mean process. Clearly the "monthly" forward premium, $\left(f_{t}-s_{t}\right)$, will also be a complicated non-linear process with long-memory characteristics. However, it is unclear how this dependence will translate into the value of the estimated slope coefficient from the anomalous regression in Eq. (7).

As discussed in Section 2, the actual results for the 5-year DM- $\$$ rolling regressions depicted in Fig. 1 indicate a very wide dispersion in the estimates, with a series of positive values occurring towards the end of the sample. However, in order to confront the stylized UIP model with the most challenging test, the model was calibrated to the longer sample of 215 monthly observations for the DM-\$ rate from January 1974 through to December 1991. As noted above, this particular sample results in the "anomalous" regression estimate of $\hat{\beta}=-2.23$.

The results for the calibrated models are presented in Tables 1-3. The six panels in each table indicate the different parameter values of the transitory AR(1) coefficient, and the two innovation variances that are used in the simulation designs. Table 1 reports the simulated two-sided 90\% confidence intervals, $(5 \%, 95 \%)$, based on 1000 replications for the mean, $\mu$, standard deviation, $\sigma$, and Ljung-Box portmanteau tests, $Q(12)$ and $Q^{2}(12)$, for up to 12th order serial correlation in the levels and the squares of the "monthly" percentage change in the spot rate. Although none of the reported designs are able to accommodate all of the DM-\$ sample statistics within these particular confidence intervals, it is clear that the simulated "monthly" spot rates are broadly consistent with the stylized empirical facts. ${ }^{11}$

Analogous results for the simulated "monthly" forward premium are reported in

${ }^{11}$ While it would be fairly easy to design a model which includes all of the particular summary statistics for the 215 monthly DM-\$ rates within the $90 \%$ confidence intervals, we deliberately did not pursue such parameter refinements, choosing instead to focus more broadly on the salient implications of the model, and the sensitivity of the estimated slope coefficients to the different model parameters. 
Table 1

Simulated monthly spot rate $\left[100\left(s_{t+1}-S_{t}\right)\right]^{\mathrm{a}}$

\begin{tabular}{llllllllllll}
\hline & $10^{5} \sigma_{\eta}^{2}$ & $10^{5} \sigma_{\epsilon}^{2}$ & $\sigma$ & $\mu$ & & $\sigma$ & & $Q(12)$ & \multicolumn{3}{c}{$Q^{2}(12)$} \\
\hline $\mathrm{N}$ & \multirow{2}{*}{3.662} & \multirow{2}{*}{3.662} & 0.995 & -0.33 & $0.32^{*}$ & 3.55 & 4.17 & 5.82 & 23.0 & 4.62 & $21.1^{*}$ \\
$\mathrm{G}$ & & & & -0.32 & $0.30^{*}$ & 2.73 & $4.12^{*}$ & 5.53 & 25.7 & 5.25 & $58.7^{*}$ \\
$\mathrm{~N}$ & 3.055 & \multirow{2}{*}{3.055} & 0.999 & -0.31 & $0.32^{*}$ & 3.28 & 3.87 & 5.56 & 22.4 & 5.05 & $20.6^{*}$ \\
$\mathrm{G}$ & & & & -0.28 & $0.28^{*}$ & 2.51 & $3.79^{*}$ & 5.80 & 25.9 & 4.89 & $52.6^{*}$ \\
$\mathrm{~N}$ & \multirow{2}{*}{1.000} & \multirow{2}{*}{8.308} & 0.995 & -0.20 & 0.19 & 3.98 & 4.68 & 6.73 & 24.4 & 5.12 & $20.5^{*}$ \\
$\mathrm{G}$ & & & & -0.18 & 0.17 & 1.86 & $5.03^{*}$ & 6.53 & $40.9^{*}$ & 6.05 & $119^{*}$ \\
$\mathrm{~N}$ & \multirow{2}{*}{1.000} & \multirow{2}{*}{5.375} & \multirow{2}{*}{0.999} & -0.23 & 0.24 & 3.36 & 3.96 & 5.32 & 20.9 & 5.18 & $21.8^{*}$ \\
$\mathrm{G}$ & & & & -0.20 & 0.20 & 1.71 & $3.84^{*}$ & 6.07 & $34.6^{*}$ & 5.43 & $10.6^{*}$ \\
$\mathrm{~N}$ & \multirow{2}{*}{5.187} & \multirow{2}{*}{1.000} & \multirow{2}{*}{0.995} & -0.37 & $0.35^{*}$ & 3.32 & 3.91 & 5.31 & 21.0 & 5.20 & $21.0^{*}$ \\
$\mathrm{G}$ & & & & -0.36 & $0.35^{*}$ & 3.11 & 3.77 & 5.59 & 22.5 & 5.21 & $25.2^{*}$ \\
$\mathrm{~N}$ & \multirow{2}{*}{4.874} & \multirow{2}{*}{1.000} & 0.999 & -0.37 & $0.35^{*}$ & 3.22 & 3.80 & 5.33 & 21.4 & 5.09 & $21.0^{*}$ \\
$\mathrm{G}$ & & & & -0.38 & $0.35^{*}$ & 2.99 & 3.69 & 5.46 & 22.5 & 4.96 & $25.5^{*}$ \\
\hline
\end{tabular}

${ }^{\text {a }}$ Note: The table reports the simulated $90 \%$ confidence intervals, $(5 \%, 95 \%)$, for the $\mathrm{N}$ and G UIP models defined by Eqs. (10)-(15). The reported fractiles are based on 1000 replications. The sample size is fixed at $T=215$, while $\theta=0.70$ and $d=0.75$. The other model parameters are as indicated. The column labelled $\mu$ refers to the sample mean, followed by the sample standard deviation, $\sigma$, and the Ljung-Box portmanteau tests for up to 12th order serial correlation in the levels and the squares of the returns denoted by $Q(12)$ and $Q^{2}(12)$, respectively. The corresponding sample values for the 215 monthly observations on the percentage DM- $\$$ appreciation from January 1974 through to December 1991, are $\mu=0.26, \sigma=2.75$, $Q(12)=30.9$, and $Q^{2}(12)=6.91$, respectively. An * indicates that the DM- $\$$ sample statistic is contained within the simulated $90 \%$ confidence interval.

Table 2

Simulated monthly forward premium $\left[100\left(f_{t}-s_{t}\right)\right]^{\mathrm{a}}$

\begin{tabular}{llllllllllll}
\hline & $10^{5} \sigma_{\eta}^{2}$ & $10^{5} \sigma_{\epsilon}^{2}$ & $\phi$ & \multicolumn{1}{l}{$\mu$} & & $\sigma$ & & $Q(12)$ & \multicolumn{3}{c}{$Q^{2}(12)$} \\
\hline $\mathrm{N}$ & \multirow{2}{*}{3.662} & \multirow{2}{*}{3.662} & 0.995 & -0.28 & $0.28^{*}$ & 0.46 & 0.72 & 406 & $1146^{*}$ & 141 & $656^{*}$ \\
$\mathrm{G}$ & & & & -0.19 & 0.13 & 0.15 & 0.68 & 337 & $1194^{*}$ & 129 & $788^{*}$ \\
$\mathrm{~N}$ & 3.055 & \multirow{2}{*}{3.055} & 0.999 & -0.24 & $0.24^{*}$ & 0.12 & $0.31^{*}$ & 832 & 2071 & 402 & $1736^{*}$ \\
$\mathrm{G}$ & & & & -0.17 & 0.12 & 0.05 & $0.24^{*}$ & 585 & $2059^{*}$ & 213 & $1808^{*}$ \\
$\mathrm{~N}$ & 1.000 & \multirow{2}{*}{8.308} & 0.995 & -0.41 & $0.47^{*}$ & 0.67 & 1.08 & 395 & $1140^{*}$ & 142 & $690^{*}$ \\
$\mathrm{G}$ & & & & -0.27 & 0.20 & 0.24 & 1.11 & 312 & $1224^{*}$ & 128 & $829^{*}$ \\
$\mathrm{~N}$ & 1.000 & \multirow{2}{*}{5.375} & 0.999 & -0.36 & $0.31^{*}$ & 0.17 & $0.40^{*}$ & 833 & 2034 & 403 & $1721^{*}$ \\
$\mathrm{G}$ & & & & -0.24 & 0.15 & 0.06 & $0.34^{*}$ & 537 & $2050^{*}$ & 164 & $1804^{*}$ \\
$\mathrm{~N}$ & 5.187 & \multirow{2}{*}{1.000} & 0.995 & -0.16 & 0.14 & 0.23 & 0.38 & 388 & $1193^{*}$ & 140 & $690^{*}$ \\
$\mathrm{G}$ & & & & -0.10 & 0.06 & 0.08 & $0.37^{*}$ & 309 & $1206^{*}$ & 124 & $817^{*}$ \\
$\mathrm{~N}$ & 4.874 & \multirow{2}{*}{1.000} & 0.999 & -0.15 & 0.14 & 0.07 & 0.18 & 827 & 2080 & 408 & $1751^{*}$ \\
$\mathrm{G}$ & & & & -0.09 & 0.08 & 0.03 & 0.15 & 760 & $2085^{*}$ & 306 & $1810^{*}$ \\
\hline
\end{tabular}

${ }^{a}$ Note: See Table 1. The corresponding sample values for the monthly DM- $\$$ forward premium from January 1974 through to December 1991, are $\mu=0.24, \sigma=0.22, Q(12)=773$ and $Q^{2}(12)=409$, respectively. 
Table 3

Simulated monthly unbiasedness regression $\left[s_{t+1}-s_{t}=\alpha+\beta\left(f_{t}-s_{t}\right)+u_{t}\right]^{\mathrm{a}}$

\begin{tabular}{|c|c|c|c|c|c|c|c|c|c|}
\hline & $10^{5} \sigma_{\eta}^{2}$ & $10^{5} \sigma_{\epsilon}^{2}$ & $\phi$ & $\alpha$ & & $\beta$ & & $R^{2}$ & \\
\hline $\mathrm{N}$ & 3.662 & 3.662 & 0.995 & -0.00 & $0.00^{*}$ & 0.46 & 1.95 & 0.008 & $0.065^{*}$ \\
\hline G & & & & -0.00 & $0.00^{*}$ & -0.04 & 2.97 & 0.001 & $0.062 *$ \\
\hline $\mathrm{N}$ & 3.055 & 3.055 & 0.999 & -0.01 & $0.01^{*}$ & -0.00 & 4.86 & 0.001 & $0.040^{*}$ \\
\hline G & & & & -0.00 & $0.01^{*}$ & -1.62 & 7.36 & 0.001 & $0.042 *$ \\
\hline $\mathrm{N}$ & 1.000 & 8.308 & 0.995 & -0.01 & $0.01^{*}$ & 0.67 & 1.83 & 0.028 & $0.088^{*}$ \\
\hline G & & & & -0.00 & $0.01 *$ & 0.42 & 2.25 & 0.010 & $0.094 *$ \\
\hline $\mathrm{N}$ & 1.000 & 5.375 & 0.999 & -0.01 & $0.01^{*}$ & 0.46 & 4.50 & 0.004 & $0.046^{*}$ \\
\hline G & & & & -0.00 & $0.01^{*}$ & -0.32 & 5.83 & 0.001 & $0.061^{*}$ \\
\hline $\mathrm{N}$ & 5.187 & 1.000 & 0.995 & -0.00 & $0.00^{*}$ & -0.07 & 2.54 & 0.001 & $0.042 *$ \\
\hline G & & & & -0.00 & $0.00^{*}$ & -1.53 & 4.35 & 0.001 & 0.037 \\
\hline $\mathrm{N}$ & 4.874 & 1.000 & 0.999 & -0.01 & $0.01 *$ & -1.40 & 6.53 & 0.001 & 0.033 \\
\hline G & & & & -0.01 & $0.01 *$ & -5.14 & $10.9 *$ & 0.001 & 0.032 \\
\hline
\end{tabular}

${ }^{\text {a }}$ Note: See Table 1. The column labelled $\alpha$ refers to the estimated intercept, followed by the estimated slope coefficient, $\beta$, and the regression coefficient of multiple correlation, $R^{2}$. The sample values for the monthly DM-\$ spot and forward exchange rates from January 1974 through to December 1991, are $\alpha=0.00, \beta=-2.23$, and $R^{2}=0.038$, respectively.

Table 2. Again, the stylized UIP model appears broadly consistent with the important features of the forward premium series. In particular, the $Q(12)$ statistics clearly indicate that the long memory, FIGARCH in the mean process is very successful in replicating the important property of very pronounced long-run serial dependence in the conditional mean of the forward premium.

The main results concerning the distribution of the slope coefficient from the anomalous regression are reported in Table 3. For the first design the $\mathrm{N}$ model, with i.i.d. normal innovations, has a $90 \%$ confidence interval for $\hat{\beta}$ equal to $(0.46,1.95)$, and a zero probability of drawing a negative value of $\hat{\beta}$. However, with the FIGARCH innovations, as in Eqs. (13) and (14), the same 90\% confidence interval becomes much wider, $(-0.04,2.97)$, and the probability of drawing a negative value of is now 0.06. Fig. 2 graphs the simulated small sample distribution for the slope coefficients for these first two simulated models and illustrates the excess dispersion produced from the model with FIGARCH in the mean and hence corresponding long memory of the forward premium. ${ }^{12}$ It is clear that the presence of persistent long memory ARCH effects makes a substantial difference to the finite sample distribution of the $\hat{\beta}$ estimates.

The next set of results in Table 3 highlight that with a more persistent "daily" transitory $\mathrm{AR}(1)$ component and $\phi=0.999$, or $(0.999)^{21} \approx 0.979$ compared to $(0.995)^{21} \approx 0.900$ at the "monthly" level, the dispersion in the distribution of the estimated slope coefficients are even wider. For the $\mathrm{G}$ error design, $5 \%$ of the estimated

\footnotetext{
12 The smooth densities were calculated by an Epanechnikov kernel and the bandwidth given by formula (3.31) in Silverman (1986).
} 


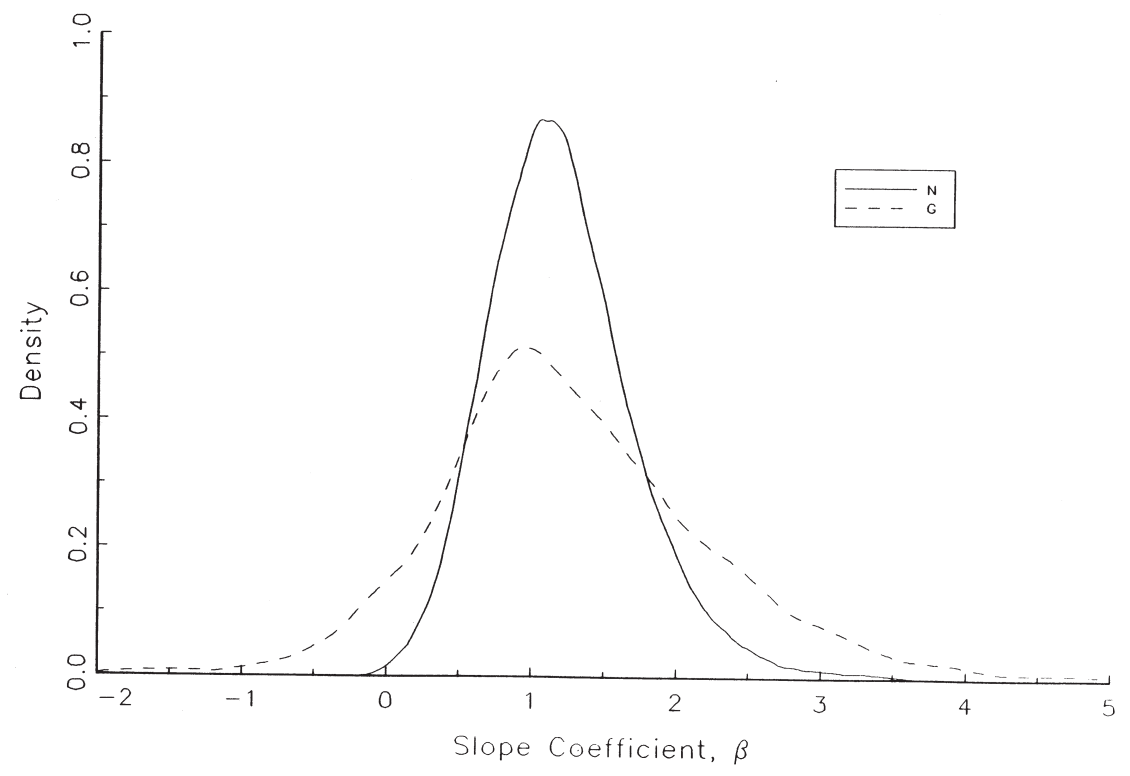

Fig. 2. Simulated unbiasedness regression. The figure graphs the kernel estimates of the simulated small sample distribution for the slope coefficients, $\beta$, in the unbiasedness regression in Eq. (7). The simulated UIP models, $\mathrm{N}$ and $\mathrm{G}$, are defined by Eqs. (10)-(15). The sample size and other model parameters are $T=215, \theta=0.70, d=0.75, \sigma_{\eta}^{2}=3.662 \times 10^{-5}, \sigma_{\epsilon}^{2}=3.662 \times 10^{-5}$, and $\phi=0.995$.

$\hat{\beta}$ 's from the "monthly" unbiasedness regressions fall below -1.62 , and $18.2 \%$ of the estimates are less than zero.

The first two parameter configurations reported in the tables both equate the innovation variances for the transitory and permanent components. The remaining four panels of Table 3 indicate the relative importance of the two components in determining the probability of an estimated slope coefficient far away from the theoretical value of unity. In particular, it is clear that the higher $\sigma_{\eta}^{2}$ and the more important the permanent component, the less informative the estimated value of $\hat{\beta}$. For instance, for the last two $\mathrm{G}$ models reported in the table, the $90 \%$ confidence intervals are extremely wide at $(-1.53,4.35)$ and $(-5.14,10.9)$, respectively. The increased width of these confidence intervals now mirrors the observed regularity of being much more likely to estimate a negative slope coefficient. In fact, the probability of estimating a negative $\beta$ in these two designs is 0.20 and 0.33 , respectively. These same effects regarding the importance of $\phi$ and $\sigma_{\eta}^{2}$ are illustrated in Fig. 3, which graphs the distribution of $\hat{\beta}$ for the $\mathrm{G}$ models for the first, second and final parameter designs.

A striking depiction of the finite sample nature of the problem is given by Fig. 4. This figure plots the density of the estimated slope coefficients for the last G data generating process based on $T=60,215$ and 2150 "monthly" observations, respectively. The anomalous regressions with only "5-years" of "monthly" observations, or $T=60$, is very uninformative about the true value of $\beta$. As such, these results accord well with the actual 5-year rolling regressions for the DM-\$ rates graphed in Fig. 


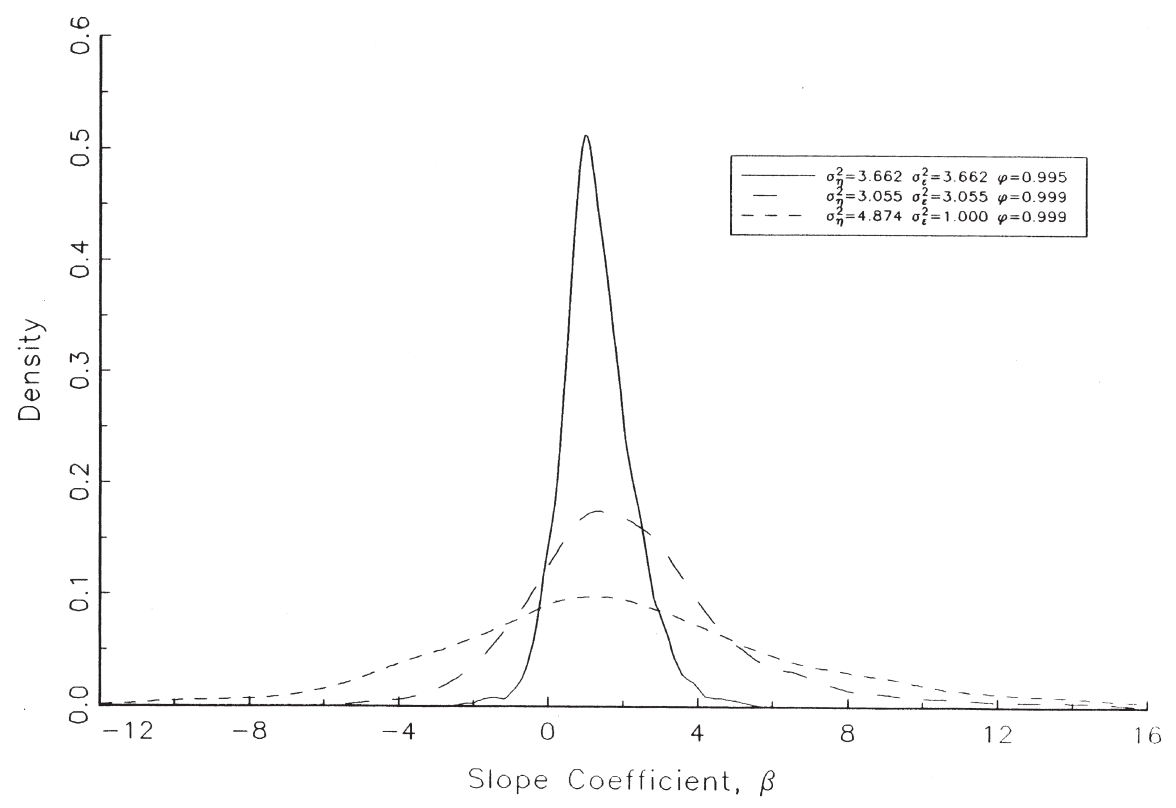

Fig. 3. Simulated unbiasedness regression. The figure graphs the kernel estimates of the simulated small sample distribution for the slope coefficients, $\beta$, in the unbiasedness regression in Eq. (7). The simulated UIP G model is defined by Eqs. (10)-(15). The sample size is fixed at $T=215$ along with $\theta=0.70$ and $d=0.75$. The other model parameters are as indicated.

1. Increasing the sample size to $T=215$ results in the aforementioned very wide confidence intervals for $\hat{\beta}$, although the distribution is now clearly centered around the true theoretical value of unity. However, for this particular UIP-FIGARCH model, even with $T=2150$ observations there is still a non-negligible probability of 0.14 of estimating $\beta$ to be less than zero. An interesting topic for future research would be to further investigate the rate of convergence of the coefficient estimate. Important progress for a simpler time series model, without FIGARCH in the mean effects, has recently been made by Maynard and Phillips (1998).

\section{Conclusion}

This paper has examined the forward premium anomaly, that in regressions of the change in the logarithm of the spot rate on the forward premium, negative slope coefficients have invariably been reported throughout the literature. First, the paper shows that with shorter samples these regressions typically generate slope coefficient estimates that are very widely dispersed and are even positive and significantly greater than one for some 5-year periods. Hence the empirical results are suggestive of slow convergence to the true parameter value of one. This conjecture is verified through a stylized UIP model, which takes the empirical facts of spot rates being 


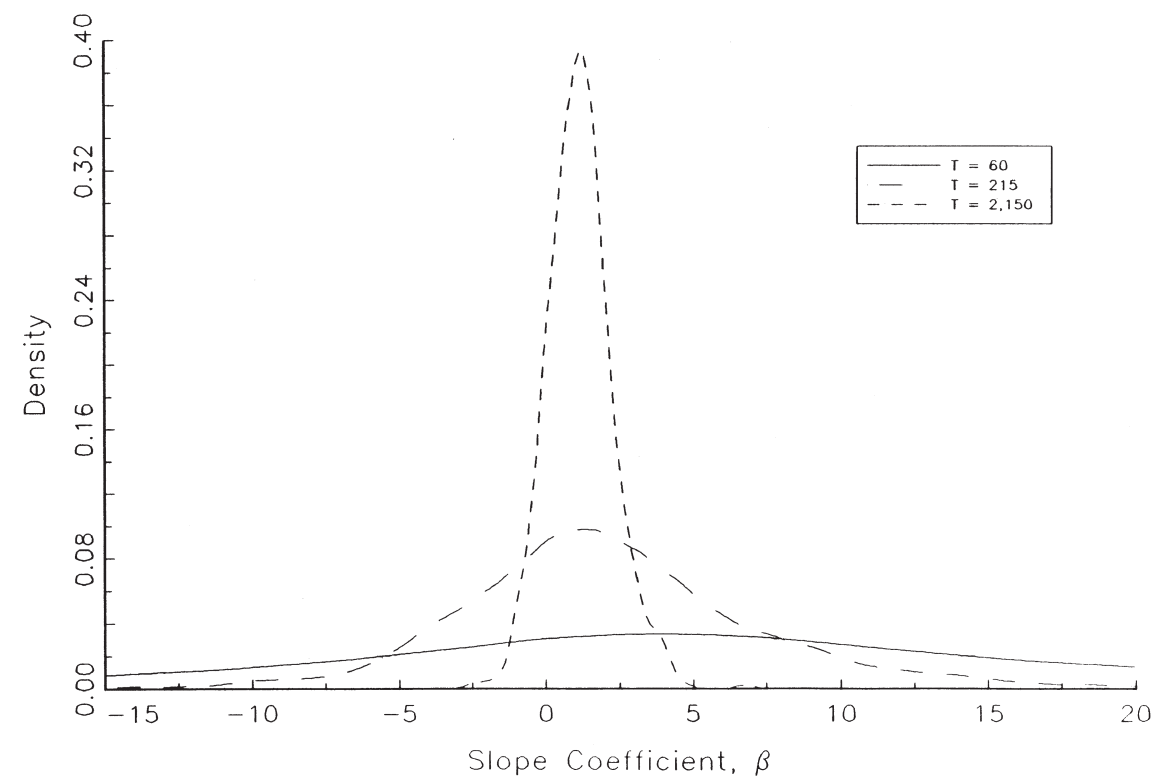

Fig. 4. Simulated unbiasedness regression. The figure graphs the kernel estimates of the simulated small sample distribution for the slope coefficients, $\beta$, in the unbiasedness regression in Eq. (7). The simulated UIP G model is defined by Eqs. (10)-(15). The model parameters are $\theta=0.70, d=0.75, \sigma_{\eta}^{2}=4.874 \times 10^{-5}$, $\sigma_{\epsilon}^{2}=1.000 \times 10^{-5}$, and $\phi=0.999$. The simulated sample sizes, $T$, are as indicated.

approximate martingale differences with very persistent volatility and generates the implied forward rate under the assumption of uncovered interest rate parity, so that the time-dependent risk premium is zero. The simulated models are found to generate the results reported in the literature. In particular, the forward premium has very persistent autocorrelation or long memory, and the slope coefficient in the famous "anomalous" regression is extremely widely dispersed.

Hence the so-called forward premium anomaly may be viewed as a statistical artifact from having small sample sizes and persistent autocorrelation in the forward premium. The "anomalous" regression estimates reported throughout the literature do not appear to provide convincing statistical evidence to reject the hypothesis of the forward rate being an unbiased predictor of the future spot rate. If a time-varying risk premium does exist, then the currently available evidence also suggests that it is extremely small at the monthly level.

While the focus of the present paper has been on the foreign exchange market, very similar issues arise in regression-based tests of the expectations hypothesis of the term structure of interest rates in which the term spread plays the role of a highly persistent forward premium. A theoretical data generating process, along the lines developed here, may help to explain some of the "anomalous" regression results reported in that literature. We leave further work along these lines for future research. 


\section{Acknowledgements}

A preliminary version of this paper was distributed under the different title of, "Explaining the forward premium anomaly: remembering long memory". The research of Bollerslev was supported by a grant from the NSF to the NBER. The paper has benefitted from helpful comments by two anonymous referees and from seminar participants at the Canadian Econometric Study Group Meetings at Waterloo University, the Mid West Macroeconomics Conference at Michigan State University, Tulane University and Washington University.

\section{References}

Andersen, T.G., Bollerslev, T., 1997. Heterogeneous information arrivals and return volatility dynamics: uncovering the long-run in high frequency returns. Journal of Finance 52, 975-1005.

Backus, D., Foressi, S., Telmer, C., 1996. Affine models of currency pricing. NBER Working Paper No. 5623.

Baillie, R.T., 1989. Tests of rational expectations and market efficiency. Econometric Reviews 8, 151-186.

Baillie, R.T., Bollerslev, T., 1989. The message in daily exchange rates: a conditional variance tale. Journal of Business and Economic Statistics 7, 297-305.

Baillie, R.T., Bollerslev, T., 1990. A multivariate generalized ARCH approach to modeling risk premia in forward foreign exchange rate markets. Journal of International Money and Finance 9, 309-324.

Baillie, R.T., Bollerslev, T., 1994. The long-memory of the forward premium. Journal of International Money and Finance 13, 309-324.

Baillie, R.T., Bollerslev, T., Mikkelsen, H.O., 1996. Fractionally integrated generalized autoregressive conditional heteroskedasticity. Journal of Econometrics 74, 3-30.

Bansal, R., 1997. An exploration of the forward premium puzzle in currency markets. Review of Financial Studies 10, 369-403.

Bekaert, G., 1995. The time variation of expected returns and volatility in foreign exchange markets. Journal of Business and Economic Statistics 13, 397-408.

Bekaert, G., 1996. The time variation of risk and return in foreign exchange markets: a general equilibrium approach. Review of Financial Studies 9, 427-470.

Bekaert, G., Hodrick, R.J., 1992. Characterizing predictable components in excess returns on equity and foreign exchange markets. Journal of Finance 47, 467-509.

Bekaert, G., Hodrick, R.J., 1993. On biases in the measurement of foreign exchange risk premiums. Journal of International Money and Finance 12, 115-138.

Bekaert, G., Hodrick, R.J., Marshall, D.A., 1997. The implications of first order risk aversion for asset market risk premiums. Journal of Monetary Economics 40, 3-39.

Bollerslev, T., Melvin, M., 1994. Bid-ask spreads and volatility in the foreign exchange market: an empirical analysis. Journal of International Economics 36, 355-372.

Crowder, W.J., 1994. Foreign exchange market efficiency and common stochastic trends. Journal of International Money and Finance 13, 551-564.

Ding, Z., Granger, C.W.J., 1996. Modeling volatility persistence of speculative returns: a new approach. Journal of Econometrics 73, 185-215.

Engel, C., 1996. The forward discount anomaly and the risk premium: a survey of recent evidence. Journal of Empirical Finance 3, 123-192.

Evans, M.D., Lewis, K.K., 1995. Do long term swings in the dollar affect estimates of the risk premia? Review of Financial Studies 8, 709-742.

Fama, E.F., 1984. Spot and forward exchange rates. Journal of Monetary Economics 14, 319-338.

Fama, E.F., French, K.R., 1988. Permanent and temporary components of stock prices. Journal of Political Economy 96, 246-273. 
Frankel, J.A., Froot, K.A., 1987. Using survey data to test standard propositions regarding exchange rate expectations. American Economic Review 77, 133-153.

Froot, K.A., Thaler, R.H., 1990. Anomalies: foreign exchange. Journal of Economic Perspectives 4, 179-192.

Hodrick, R.J., 1987. The Empirical Evidence on the Efficiency of Forward and Futures Foreign Exchange Markets. Harwood Academic Publishers, Chur., Switzerland.

Hsieh, D.A., 1989. Modeling heteroskedasticity in daily foreign exchange rates. Journal of Business and Economic Statistics 7, 307-317.

Macklem, R.T., 1991. Forward exchange rates and risk premiums in artificial economies. Journal of International Money and Finance 10, 365-391.

McCallum, B.T., 1994. A reconsideration of the uncovered interest rate parity relationship. Journal of Monetary Economics 33, 105-132.

Maynard, A., Phillips, P.C.B., 1998. Rethinking an old empirical puzzle: econometric evidence on the forward discount anomaly. Yale University working paper.

Poterba, J.M., Summers, L.H., 1988. Mean reversion in stock prices, evidence and implications. Journal of Financial Economics 22, 27-58.

Silverman, B.W., 1986. Density Estimation for Statistics and Data Analysis. Chapman and Hall, New York. 